\title{
The Analysis of Ricardian Model under the Production Possibility Frontier
}

\author{
SU Ming, DAI Xue-Mei, ZHANG Qi, ZHOU Yong-Hui \\ School of Big Data and Computer Science, Guizhou Normal University, GuiYang, China \\ suming629@163.com,845329407@qq.com,99873436@qq.com,yonghuizhou@163.com
}

\begin{abstract}
Ricardian model as the cornerstone of the theory of comparative advantage considers a linear production possibility frontier and shows that the marginal rate of substitution is constant. However, production possibility frontier is often nonlinear in real life. In this paper we give a full mathematical analysis of Ricardian model especially under nonlinear production possibility frontier, find that comparative advantage makes total profits increasing and both win, and point out that both countries will win within the range of mutual beneficial trading prices. But, if both of the comparative advantages are not enough, the both countries will lose. For the line of formulating allocation is not parallel to the line of best optimal allocation, and the range of mutual beneficial trading makes the tangent of allocation lines within the tangents at the product equilibrium in closed system. Finally, several problems should be paid attention to the comparative advantage.
\end{abstract}

Keywords-Ricardo Model; production possibility frontier; comparative advantage; mathematical analysis

\section{INTRODUCTION}

As a milestone of the theory of comparative advantage, Ricardian model[1] is the basic conjunct win theory in international trades, original economic trades and other social fields, in which the product possibility frontier is linear. Then, many others author followed the idea to study economic problems, see[2-4].

However, product possibility frontier is often nonlinear $[5,6]$. In this paper we give a full mathematical analysis of Ricardian model especially under nonlinear production possibility frontier and show that comparative advantage can make total profits increase, cooperation win-win and prices mutual beneficial. Finally we point out several problems that should be paid attention to the comparative advantage.

\section{RicARDiAN MODEL UNDER A LINEAR PRODUCT POSSIBILITY FRONTIER}

In Ricardian model there are two counties, two kinds of goods and one element. Assume that country A and country B both produce goods $\mathrm{X}$ and $\mathrm{Y}$. And the labor rates of $\mathrm{X}$ and $\mathrm{Y}$ in Country $\mathrm{A}$ are $a_{X}, a_{Y}$ respectively, while the labor rates of $\mathrm{X}$ and $\mathrm{Y}$ in country $\mathrm{B}$ are $b_{X}, b_{Y}$ respectively. Ricardo shows that if $\frac{a_{X}}{b_{X}}>\frac{a_{Y}}{b_{Y}}$ then on goods $\mathrm{X}$, country $\mathrm{A}$ has a comparative advantage while on goods $\mathrm{Y}$ country B has a comparative advantage.

\section{A. Comparative Advantage Makes Total Profits Increasing}

On the product possibility boundary, if the product of $\mathrm{X}$ is $x_{A} \in\left[0, a_{x}\right]$, then the total product in country $\mathrm{A}$ is

$$
Q_{A}=x_{A}+a_{y}-\frac{a_{y}}{a_{x}} x_{A},
$$

And the total product in country B is

$$
Q_{B}=x_{B}+b_{y}-\frac{b_{y}}{b_{x}} x_{B}, \text { for } x_{B} \in\left[0, b_{x}\right] \text {. }
$$

Then the total is

$$
Q=a_{y}+b_{y}+x_{A}+x_{B}-\frac{a_{y}}{a_{x}} x_{A}-\frac{b_{y}}{b_{x}} x_{B} .
$$

Differentiating it, we get

$$
d Q=\left(1-\frac{a_{y}}{a_{x}}\right) d x_{A}+\left(1-\frac{b_{y}}{b_{x}}\right) d x_{B} .
$$

It is easy to see that

(1) if $\frac{a_{y}}{a_{x}}<\frac{b_{y}}{b_{x}}$, then one unite change of $x_{A}$ will cause a larger change $Q$ of than that of $x_{A}$, that is , country A has a comparative advantage on $\mathrm{X}$. And if $x_{A}=a_{x}$ and $x_{B}=0$, then $Q$ reaches maximum, $Q_{\max }=a_{x}+b_{y}$, where $\mathrm{H}$ is the optimal in Figure 1 below. 


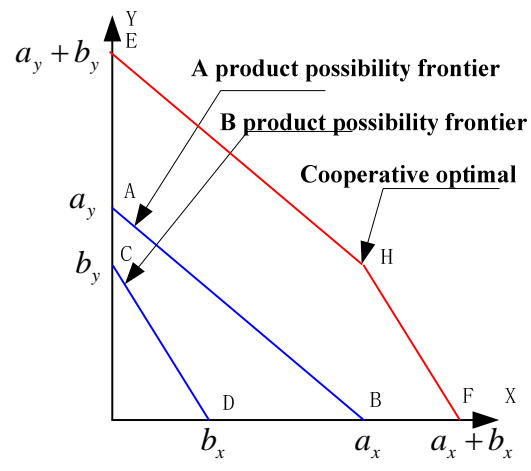

Fig.1. County A has a comparative advantage on goods Y

In Fig. 1, line A is the product possibility frontier of country $\mathrm{A}$, line $\mathrm{CD}$ is the product possibility frontier of country $\mathrm{B}$, and broken line EHF is the product possibility frontier of the two countries A and B when cooperation.

(2) if $\frac{a_{y}}{a_{x}}=\frac{b_{y}}{b_{x}}$, then a unite change of $x_{A}$ cause the same change of $Q$ as that of $y_{B}$, that is there is no comparative advantage between country $\mathrm{A}$ and $\mathrm{B}$.

\section{B. Comparative Advantage Makes Both Win}

As we know, in a closed system, for country A, the unit of $\mathrm{X}$ to exchange $\mathrm{Y}$ is equivalent to the labor exchange rate $a_{y} / a_{x}$; for country $\mathrm{B}$, the unit of $\mathrm{Y}$ to exchange $\mathrm{X}$ is equivalent to the labor exchange rate $b_{x} / b_{y}$. So if $\frac{a_{y}}{a_{x}}<\frac{b_{y}}{b_{x}}$, there is a comparative advantage, and country A should exchange $\mathrm{X}$ to goods $\mathrm{Y}$ of country B while country B should exchange $\mathrm{Y}$ to goods $\mathrm{X}$ of country $\mathrm{A}$. And for country A, the quantity $M_{A}$ of $\mathrm{Y}$ exchanging to a unite $\mathrm{X}$ is bigger than $a_{y} / a_{x}$, and country A would like to exchange $\mathrm{Y}$ to $\mathrm{X}$ for the increasing total profits, and vice versa.

For country $\mathrm{A}$, the product equilibrium in closed system is $\left(x_{A}, f\left(x_{A}\right)\right)$ with total product $Q_{A}=x_{A}+f\left(x_{A}\right)$, which is $Q_{A F}=\frac{a_{y}}{a_{x}} \square x_{A}+f\left(x_{A}\right)$ if $\mathrm{Y}$ is considered as the standard value. And in an open system, the total product is $Q_{A}=a_{x}$, which is $Q_{A k}=M_{A} \square a_{x}$ if $\mathrm{Y}$ is as the standard value.

So the increment

$$
\Delta Q_{A}=Q_{A k}-Q_{A F}=M_{A} \square a_{x}-\left(\frac{a_{y}}{a_{x}} \square x_{A}+f\left(x_{A}\right)\right)
$$

Or

$$
\Delta Q_{A}==x_{A} \square\left(M_{A}-\frac{a_{y}}{a_{x}}\right)+\left(\left(M_{A} \square a_{x}-x_{A}\right)-f\left(x_{A}\right)\right)
$$

Then, if $M_{A}>\frac{a_{y}}{a_{x}}$,we have

$$
\left(M_{A} \square a_{x}-x_{A}\right)-f\left(x_{A}\right)>0,
$$

That is $\Delta Q_{A}=Q_{A k}-Q_{A F}>0$.

Similarly, we have

$$
\Delta Q_{B}=Q_{B k}-Q_{B F}>0,
$$

Where $Q_{B k}$ is the total product when country $\mathrm{B}$ is in development status, and $Q_{B F}$ is the total product when country $\mathrm{B}$ is in closed status.

Now the indifference curve is as figure 2 below.

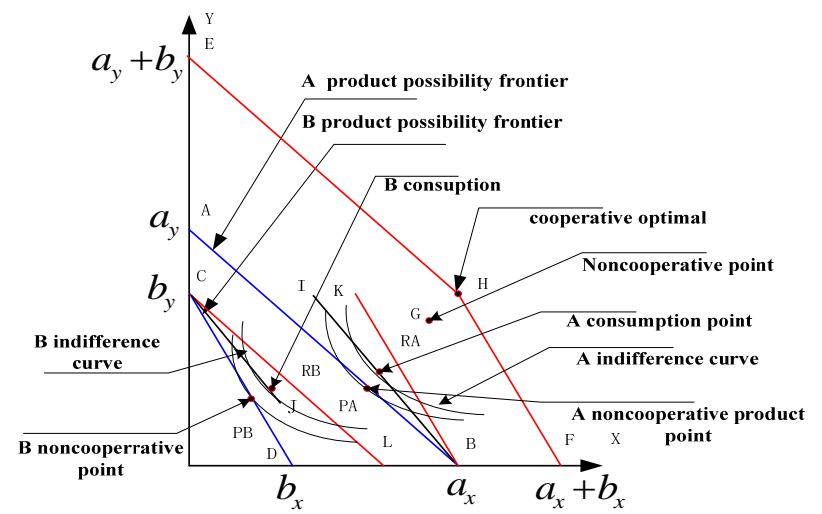

Fig.2. Comparative advantage makes both win

In Fig.2, point $\mathrm{PA} / \mathrm{PB}$ is the product point of country $\mathrm{A} / \mathrm{B}$ in closed system (i.e. the tangent point between the product possibility frontier and the indifference curve in country A?B), point $\mathrm{RA} / \mathrm{RB}$ is the consumption point (i.e., the tangent point between the allocation line and the indifference curve), which shows the increasing of warfare in both country.

\section{Mutual Trading Prices}

(1) Relation of trading prices

Clearly, the quantity of $\mathrm{X}$ put by country $\mathrm{A}$ is equal to that of $\mathrm{Y}$ called by $\mathrm{B}$, while the quantity of $\mathrm{Y}$ put by country $\mathrm{B}$ is equal to that of $\mathrm{X}$ called by $\mathrm{A}$, that is

$$
\begin{aligned}
& M_{A} \square \Delta x_{A}=\Delta y_{B}, M_{B} \square \Delta y_{B}=\Delta x_{A} . \\
& \text { So } M_{A}=\frac{1}{M_{B}} .
\end{aligned}
$$




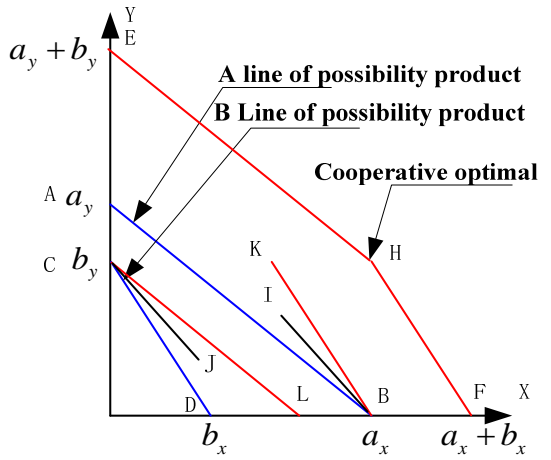

Fig.3. Relation of trading prices and mutual beneficial prices

That is to say, the price $M_{A}$ of one unit $\mathrm{X}$ in country A to exchange goods $\mathrm{Y}$ in country $\mathrm{B}$ is equal to the inverse of the price $M_{B}$ of one unit $\mathrm{Y}$ in country $\mathrm{B}$ to exchange goods $\mathrm{X}$ in country A, according to the pricing of $\mathrm{Y}$.

From Fig.3, the relation of trading price means that the allocation line BI of country A is parallel to the allocation line CJ of country B.

(2) Range of mutual beneficial prices

$$
\begin{aligned}
& \text { If } M_{A}>\frac{a_{y}}{a_{x}} \text { and } M_{B}>\frac{b_{x}}{b_{y}} \text {, then } \\
& \frac{a_{y}}{a_{x}}<M_{A}<\frac{b_{y}}{b_{x}}, \text { or } \frac{b_{x}}{b_{y}}<M_{B}<\frac{a_{x}}{a_{y}} .
\end{aligned}
$$

That is, if $\frac{a_{y}}{a_{x}}<M_{A}<\frac{b_{y}}{b_{x}}\left(\frac{b_{x}}{b_{y}}<M_{B}<\frac{a_{x}}{a_{y}}\right)$, then both countries have mutual beneficial trading, and we get the range of mutual prices before.

From Fig.3, the range of mutual prices reflects that the allocation line BI of country A is taken shape by the optimal allocation line $\mathrm{BK}$ and product possibility line $\mathrm{AB}$, while the allocation line $\mathrm{CJ}$ of country $\mathrm{B}$ is taken shape by the optimal allocation line $\mathrm{CL}$ and product possibility line $\mathrm{CD}$.

\section{RiCARDIAN MOdEL UNDER A NONLINEAR PRODUCT POSSIBILITY FRONTIER}

In general there are three classical shapes of product possibility: (1) convex, (2) concave and (3) line, which corresponding to increasing, decreasing and unchanging of the economical size profit

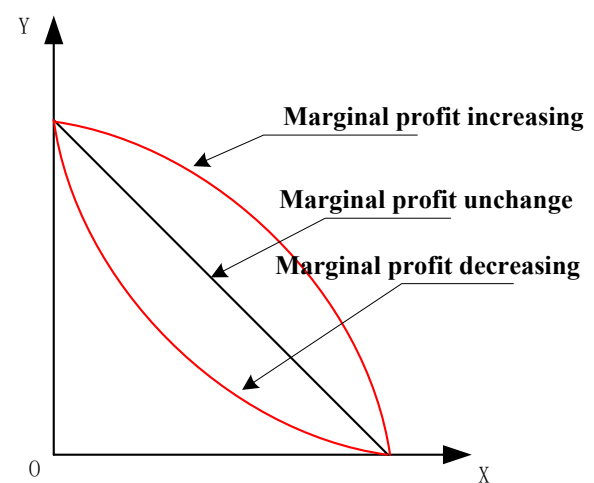

Fig. 4. Curves of product possibility

(1) If the size profit is increasing, i.e. the opportunity cost is decreasing, then the marginal rate of transfer MRT is decreasing, or, $M_{x y}=-\frac{d y}{d x}$ is decreasing, so $\frac{d^{2} y}{d x^{2}}>0$.

(2) If the size profit is not changed, i.e. the opportunity cost is not changed then the marginal rate of transfer MRT is not changed, or, $M_{x y}=-\frac{d y}{d x}=c$, then $\frac{d\left(M_{x y}\right)}{d x}=-\frac{d^{2} y}{d x^{2}}=0$, or $\frac{d^{2} y}{d x^{2}}=0$.

Now the mathematical analysis of comparative advantages as follows when the product possibility frontier is nonlinear.

\section{A. Comparative Advantage Makes Total Profits Increasing}

Assume that the product possibility frontier in country A (country B) is a continuous second differential nonlinear function $y=f(x)(y=g(x))$.

Then the quantity of country A on product $\mathrm{X}$ is

$$
Q_{A}=x_{A}+f\left(x_{A}\right) x_{A} \in\left[0, a_{x}\right] \text {, }
$$

And the quantity of country $\mathrm{B}$ on product $\mathrm{Y}$ is

$Q_{B}=x_{B}+g\left(x_{B}\right) x_{B} \in\left[0, b_{x}\right]$.

So the total is

$$
Q=x_{A}+x_{B}+f\left(x_{A}\right)+g\left(x_{B}\right) \text {. }
$$

Differentiating it, we have

$$
\begin{aligned}
& \frac{\partial Q}{\partial x_{A}}=1+\frac{d f\left(x_{A}\right)}{d x_{A}}, \\
& \frac{\partial Q}{\partial x_{B}}=1+\frac{d g\left(x_{B}\right)}{d x_{B}} .
\end{aligned}
$$


(1) If $\frac{\partial Q}{\partial x_{A}}=1+\frac{d f\left(x_{A}\right)}{d x_{A}}>\frac{\partial Q}{\partial x_{B}}=1+\frac{d g\left(x_{B}\right)}{d x_{B}}$,or $\frac{d f\left(x_{A}\right)}{d x_{A}}>\frac{d\left(x_{B}\right)}{d x_{B}}$,then one unite change of $x_{A}$ will cause a larger change $\mathrm{Q}$ of than that of $X_{B}$, that is, country A has a comparative advantage on $\mathrm{X}$ while country $\mathrm{B}$ has a comparative advantage on $\mathrm{Y}$.

(2) if $\frac{\partial Q}{\partial x_{A}}=1+\frac{d f\left(x_{A}\right)}{d x_{A}}<\frac{\partial Q}{\partial y_{B}}=1+\frac{d g\left(x_{B}\right)}{d x_{B}}$,or $\frac{d f\left(x_{A}\right)}{d x_{A}}<\frac{d\left(x_{B}\right)}{d x_{B}}$ then both unit changes of $x_{A}$ and make the same change of $Q$, so there is no comparative advantage between them.

So by Ferma maximum theory, the necessary maximum condition on $Q$ is

$$
\left\{\begin{array} { l } 
{ 1 + \frac { d f ( x _ { A } ) } { d x _ { A } } = 0 } \\
{ 1 + \frac { d g ( x _ { B } ) } { d x _ { B } } = 0 }
\end{array} \Rightarrow \left\{\begin{array} { l } 
{ \frac { d f ( x _ { A } ) } { d x _ { A } } = - 1 } \\
{ \frac { d g ( x _ { B } ) } { d x _ { B } } = - 1 }
\end{array} \Rightarrow \left\{\begin{array}{l}
\left.\frac{d f(x)}{d x}\right|_{x_{A}}=-1 \\
\left.\frac{d g(x)}{d x}\right|_{x_{B}}=-1
\end{array} .\right.\right.\right.
$$

That is, $Q$ reaches maximum when $\left.\frac{d f(x)}{d x}\right|_{x_{A}}=\left.\frac{d g(x)}{d x}\right|_{x_{B}}=-1$.

When the size profit is increasing, or the opportunity cost is decreasing the marginal rate of transfer $M_{x y}=-\frac{d y}{d x}$ is decreasing if the product possibility curve is concave, and then $\frac{d^{2} y}{d x^{2}}<0$, so $Q$ has a maximum. Of course, the results in linear case are the same as in Ricardian model.

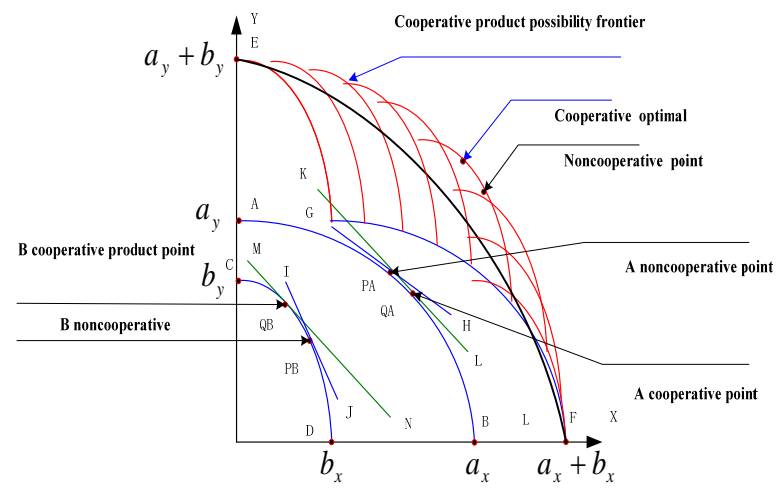

Fig.5. Comparative advantage makes total profits increasing
In Fig.5,the curve $\mathrm{AB}$ is the product possibility frontier of country $\mathrm{A}$, the curve $\mathrm{CD}$ is the product possibility frontier of country $\mathrm{B}$, and the curve $\mathrm{EF}$ is the product possibility frontier of cooperation between $\mathrm{A}$ and . The point PA is the equilibrium of country A in a closed system. The line KL satisfies $\left.\frac{d f(x)}{d x}\right|_{x_{A}}=-1$, being tangent to the curve $\mathrm{AB}$ with tangent point $\mathrm{QA}$, which is the optimal of country A when both product, while the line MN satisfies $\left.\frac{d g(x)}{d x}\right|_{x_{B}}=-1$ being tangent to the curve $\mathrm{CD}$ with tangent point $\mathrm{QB}$, which is the optimal of country B when both product.

\section{B. Comparative Advantage Makes Both Win}

Assume that in a closed system the product equilibrium of country A (country B) is $\left(x_{A}, f\left(x_{A}\right)\right)\left(x_{B}, g\left(x_{B}\right)\right)$, then the equivalent labor rate of exchange $\mathrm{X}$ to $\mathrm{Y}$ is $-\left.\frac{d f(x)}{d x}\right|_{x_{A}}$ $\left(-1 /\left.\frac{d g(x)}{d x}\right|_{x_{B}}\right)$. So if country $\mathrm{A}$ has a comparative advantage on $\mathrm{X}$ and country $\mathrm{B}$ has a comparative advantage on $\mathrm{Y}$, then $\mathrm{A}$ products $\mathrm{X}$ more and gives up producing $\mathrm{Y}$ and then exchange $\mathrm{X}$ to $\mathrm{Y}$, and vice versa. Since for country A, the quantity $M_{A}$ of the unit of $\mathrm{X}$ exchanging to $\mathrm{Y}$ in country $\mathrm{B}$ is bigger than $-\left.\frac{d f(x)}{d x}\right|_{x_{A}}$, country A would like to exchange $\mathrm{X}$ to $\mathrm{Y}$ and make total profits increasing, and vice versa.

For country $\mathrm{A}$ in a closed system the total quantity is $Q_{A}=x_{A}+f\left(x_{A}\right)$ at the product equilibrium $\left(x_{A}, f\left(x_{A}\right)\right)$, which in Y's value standard is

$$
Q_{A F}=-\left.\frac{d f(x)}{d x}\right|_{x_{A}} \square x_{A}+f\left(x_{A}\right) .
$$

In an open status, the total quantity is $Q_{A}=x_{A}+\Delta x+f\left(x_{A}+\Delta x\right)$, which in Y's value standard is $Q_{A k}=M_{A} \square\left(x_{A}+\Delta x\right)+f\left(x_{A}+\Delta x\right)$. So the increment is

$$
\Delta Q_{A}=M_{A} \square\left(x_{A}+\Delta x\right)+f\left(x_{A}+\Delta x\right)+\left.\frac{d f(x)}{d x}\right|_{x_{A}} \square x_{A}-f\left(x_{A}\right),
$$

or

$$
\Delta Q_{A}=x_{A} \square\left(M_{A}+\left.\frac{d f(x)}{d x}\right|_{x_{A}}\right)+\left(\left(f\left(x_{A}+\Delta x\right)-f\left(x_{A}\right)\right)-M_{A} \square \Delta x\right) .
$$


Since at $\left(x_{A}, f\left(x_{A}\right)\right)$, country A has a comparative advantage, then if $M_{A}>-\left.\frac{d f(x)}{d x}\right|_{x_{A}}$ we have

$$
\begin{aligned}
M_{A}+\left.\frac{d f(x)}{d x}\right|_{x_{A}}>0, \text { or } \\
M_{A}<\frac{f(x+\Delta x)-f(x)}{\Delta x} \Rightarrow(f(x+\Delta x)-f(x))-M_{A} \square \Delta x>0
\end{aligned}
$$

Thus, $\Delta Q_{A}=Q_{A k}-Q_{A F}>0$.

Similarly, we have $\Delta Q_{B}=Q_{B k}-Q_{B F}>0$.

The indifference curve is as in Fig.6.

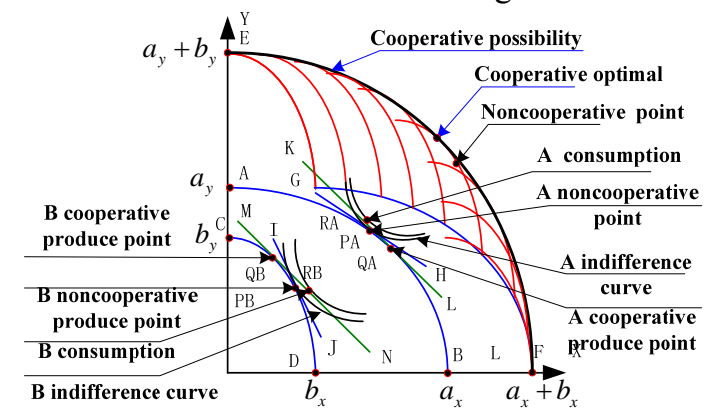

Fig. 6. Comparative advantage makes both win

\section{Mutually beneficial Trading Prices}

(1) Relation of trading prices

Clearly, the quantity of $\mathrm{X}$ put by country $\mathrm{A}$ is equal to that of $\mathrm{Y}$ called by $\mathrm{B}$, while the quantity of $\mathrm{Y}$ put by country $\mathrm{B}$ is equal to that of $\mathrm{X}$ called by $\mathrm{A}$, that is

$$
M_{A} \square \Delta x_{A}=\Delta y_{B}, M_{B} \square \Delta y_{B}=\Delta x_{A} .
$$

Then,

$$
M_{A}=\frac{1}{M_{B}} \text {. }
$$

That is to say, the price $M_{A}$ of one unit $\mathrm{X}$ in country A to exchange goods $\mathrm{Y}$ in country $\mathrm{B}$ is equal to the inverse of the price $M_{B}$ of one unit $\mathrm{Y}$ in country $\mathrm{B}$ to exchange goods $\mathrm{X}$ in country A, according to the pricing of $\mathrm{Y}$. the relation of trading price means that the allocation line KL of country A is parallel to the allocation line $\mathrm{MN}$ of country $\mathrm{B}$.

(2) Range of mutual beneficial prices

$$
\text { If } M_{A}>-\left.\frac{d f(x)}{d x}\right|_{x_{A}} \text { and } M_{B}>-1 /\left.\frac{d g(x)}{d x}\right|_{x_{B}}
$$

$$
\begin{gathered}
\text { Then }-\left.\frac{d f(x)}{d x}\right|_{x_{A}}<M_{A}<-\left.\frac{d g(x)}{d x}\right|_{x_{B}}, \\
\text { or }-1 /\left.\frac{d g(x)}{d x}\right|_{x_{B}}<M_{B}<-1 /\left.\frac{d f(x)}{d x}\right|_{X_{A}} .
\end{gathered}
$$

That is to say, under the above conditions, both country win within the range of mutual beneficial trading prices.

When both countries are in the optimal, then

$$
\begin{aligned}
& M_{A}=-\left.\frac{d f(x)}{d x}\right|_{x_{A}}=-\left.\frac{d g(x)}{d x}\right|_{x_{B}}=1, \\
& M_{B}=-1 /\left.\frac{d f(x)}{d x}\right|_{x_{A}}=-1 /\left.\frac{d g(x)}{d x}\right|_{x_{B}}=1 .
\end{aligned}
$$

However, if both of the comparative advantage is not enough or over, then both countries will lose, for the line of formulating allocation is not parallel to the line of best optimal allocation, and the rang of mutual beneficial trading makes the tangent of allocation line within the tangents at the product equilibrium in closed system, as in Fig.7 and 8,

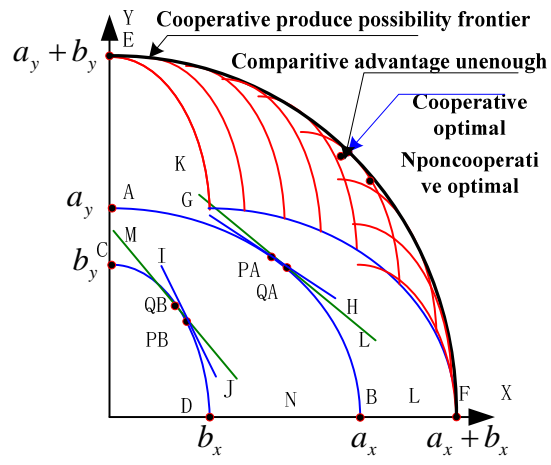

Fig.7. Comparative advantage is not enough

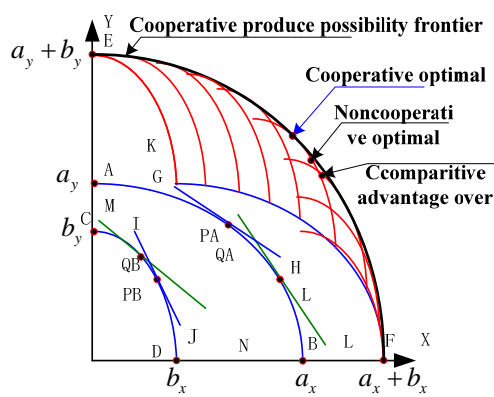

Fig.8. Comparative advantage is over 


\section{CONCLUSIONS}

By comparing our model under nonlinear product possibility frontier with Ricardian model in linear case, we can draw the following results:

(1) Ricardian model is a special case of our model;

(2) If there is a linear product frontier, the condition of comparative advantage is the tangent of product possibility frontier, and has nothing to do with labor more or less, which makes unified between Smith model and Ricardian model.

(3) Comparative advantage makes total profits increasing.

(4) Comparative advantage makes both countries win.

(5) In our nonlinear model the optimal of comparative advantage is that both countries produce a pair of the two goods, and there are three cases of comparative advantage, not enough, sufficiency or over, while in Ricardian model under a linear product possibility frontier, the optimal is that both countries produce only one different goods, and there are only two cases of comparative advantage, not enough or sufficiency.

And we can learn from the above that
(1) We should enhance the whole level of product possibility frontier to avoid falling in the strap "comparative advantage";

(2) We should look comparative advantage in a dynamic view, and foster our key competitive ability, especially when we are in a weaker status;

(3) We should develop our comparative advantage properly, prevent from being not enough or over.

\section{REFERENCES}

[1] D. Ricardo. On the Principles of Political Economy and Taxation.Bejing, The commercial Press , 1976. (In Chinese)

[2] Zhiming Zhang. Evolution of comparative advantage and Industry development . Xiamen Unversity Docoral dissertation,2002. (In Chinese)

[3] Jianhong Lin, Yuankang Xu. Comparative study of comparative advantage and competitive advantage. Business Study, 2004. (In Chinese)

[4] Shijun Wang. Comprehensive comparitive advantage thoery with empirical study. Zhejiang Unversity Docoral dissertation,2008. (In Chinese)

[5] Michael P. Todaro, Stephen C. Smith. Economic Development Addison Wesley, 2005.

[6] N. Gregory Mankiw. Principles of Economics. Beijing, Peking University Press, 2006. (In Chinese) 